\title{
Reproductive health problems and their awareness among adolescent girls: a clinical study
}

\author{
Sumedha Sharma ${ }^{1 *}$, Puja Sharma ${ }^{2}$
}

\begin{abstract}
${ }^{1}$ Department of Obstetrics and Gynecology, Hamdard Institute of Medical Sciences and Research, New Delhi, India ${ }^{2}$ Department of Obstetrics and Gynecology, Daksh Clinic, New Delhi, India
\end{abstract}

Received: 28 August 2019

Accepted: 10 September 2019

\section{*Correspondence:}

Dr. Sumedha Sharma,

E-mail: drsumedha78@gmail.com

Copyright: (c) the author(s), publisher and licensee Medip Academy. This is an open-access article distributed under the terms of the Creative Commons Attribution Non-Commercial License, which permits unrestricted non-commercial use, distribution, and reproduction in any medium, provided the original work is properly cited.

\section{ABSTRACT}

Background: The adolescent girls constitute a heterogeneous group who are at risk of various reproductive and gynecological problems. A number of health schemes are already aimed at targeting the needs of this special population. This study was aimed at identifying the special needs of this population group in respect of medical and reproductive health so as to provide a feedback for ongoing health schemes.

Methods: This study was a cross sectional analytical study conducted among adolescent girls attending various government and public schools in Lucknow city and adolescent girls presenting to Gynecology OPD of Queen Mary's Hospital for various complaints in a span of one year from June 2007 to June 2008. After taking consent, the girls were subjected to a questionnaire consisting of epidemiological parameters and questions regarding menstruation, pregnancy, birth spacing, contraception, abortion, RTI/STD, sex education. This data was later analysed. Those presenting to the OPD of Queen Mary Hospital were subjected to further examination and tests depending on their complaints.

Results: A total of 1127 adolescent girls in the age group of 10-19 consented and were included in the study. Awareness regarding the contraceptive methods available was present in only $57.8 \% .14 \%$ (164) girls were aware of reproductive tract infections and sexually transmitted diseases. However, 61\% (687) girls were aware about HIV/AIDS in particular. The mean age at menarche was $11.9 \pm 1.0$ years. $21.5 \%$ had some menstrual problem. There were 34 cases of teenage pregnancy.

Conclusions: Our study revealed substantial lacunae in the knowledge and attitude of young adolescent girls towards reproductive and sexual health. Despite various targeted health programs from the government, there is a still a need to further our efforts to improve access to health care and adopt methods to improve awareness regarding the health issues of adolescents.

Keywords: Adolescents, Contraception, HIV, Menstrual complaints, Reproductive health, Sexually transmitted diseases

\section{INTRODUCTION}

Adolescent age group is defined as those between age group of 10-19 years. Adolescents comprise 30\% of the Indian population i.e. almost 253 million. ${ }^{1}$ Such a large group represents a major human resource that can and must contribute to overall development of the country. Addressing their needs will contribute not only to social and economic development, but also to social harmony, gender parity, population stabilization and improved quality of life. The adolescent period is characterized by major biological changes like physical growth, sexual 
maturation and psycho-social development. The adolescent girls constitute a heterogeneous group of literate-illiterate, rural-urban, married-unmarried and privileged-under privileged girls who are at risk of various reproductive and gynecological problems. A number of health programs have also been initiated by the Government of India such as Rashtriya Kishore Swasthya Karyakram, RMNCH+A to address the special needs of the adolescent population Hence, there is a need to conduct studies appropriate to the needs of these different groups so as to provide a feedback regarding the efficacy of such schemes and help policy makers to further develop appropriate awareness, educational and health programs.

The objective of this study was to study the incidence of various reproductive and medical health problems in adolescent girls and to assess the awareness among adolescent girls regarding reproductive health issues.

\section{METHODS}

This study was a cross sectional analytical study conducted among adolescent girls attending various government and public schools in Lucknow city and adolescent girls presenting to Gynecology OPD of Queen Mary's Hospital for various complaints in a span of one year from June 2007 to May 2008.

Age of the girls was the only inclusion criteria irrespective of literacy, socio-economic status.

Informed consent was taken from respective institutions and guardians of girls prior to inclusion in the study. All adolescent girls were subjected to structured questionnaire and were assured of confidentiality. The questionnaire consisted of information regarding epidemiological parameters such as age, literacy status, and economic status. They were enquired about awareness regarding menstruation, pregnancy, birth spacing, contraception, abortion, RTI/STD. Their opinion regarding sex education and the source of information was also recorded. Those presenting to the OPD of Queen Mary Hospital were subjected to further examination and tests depending on their complaints. The exclusion criteria were girls who did not consent for the study.

\section{Statistical analysis}

The collected data was statistically analysed using STATA 9.0 (College Station, Texas, USA).

\section{RESULTS}

A total of 1127 adolescent girls in the age group of 10-19 consented and were included in the study. Of these, 858 girls were from Government and public schools and 269 were adolescents attending Gynecology OPD for various complaints. The mean age of girls in the study was $16.2 \pm 1.3$ years. Maximum numbers of girls were in the age group of 14-16 years (Table 1). $82 \%$ of the girls were from urban areas and $18 \%$ girls had a rural background.

Table 1: Age distribution $(\mathrm{n}=1127)$.

\begin{tabular}{|ll|}
\hline Age (years) & Number of girls \\
\hline $11-13$ & $13(1.2 \%)$ \\
\hline $14-16$ & $660(58.6 \%)$ \\
\hline $17-19$ & $454(40.3 \%)$ \\
\hline
\end{tabular}

Married girls constituted $10 \%$ of the study group. $5.8 \%$ of the girls were illiterate, $7.9 \%$ had studied up to primary level and $86.4 \%$ had education of high school and above. On the basis of per capita income, $25 \%$ girls belonged to poor socio-economic strata while the rest were middle and upper class.

$83.9 \%$ (946) were aware of legal age for marriage in India i.e. for men 21 years and for women 18 years.

Awareness regarding the contraceptive methods available was present in only $57.8 \%$ (652) girls. However, most were not aware of the places from where to procure these or the health personnel to be approached regarding counseling. $326(50 \%)$ girls had knowledge about OCPs and condoms.

Dismal 14\% (164) girls were aware of reproductive tract infections and sexually transmitted diseases. 61\% (687) girls were aware about HIV/AIDS, though there were numerous myths and beliefs with regards its transmission.

Regarding the source of reproductive health information, $44.3 \%$ relied on friends, $38.3 \%$ on books and media and $15.8 \%$ received information from elder family members. $903(80.1 \%)$ girls were aware of the normal menstrual pattern.

The mean age at menarche was $11.9 \pm 1.0$ years. The mean length of the menstrual cycle was $29.5 \pm 8.0$ days with a mean duration of flow of $4.4 \pm 1.4$ days.

Table 2: Menstrual disorders.

\begin{tabular}{|ll|}
\hline Menstrual disorders & \\
\hline Dysmenorrhea & $91(37.4 \%)$ \\
\hline Meno/metrorrhagia & $71(29.2 \%)$ \\
\hline Oligo/hypomenorrhea & $64(26.3 \%)$ \\
\hline Irregular cycles & $17(6.9 \%)$ \\
\hline
\end{tabular}

243 girls $(21.5 \%)$ had menstrual problems. Of these, the most common menstrual complaint was dysmenorrhea (37\%). Others were menorrhagia/metrorrhagia in $29 \%$, primary/secondary amenorrhea in $28 \%$, oligo/hypomenorrhea in $26 \%$ and $6.9 \%$ had irregular cycles (Table 2).

However, only $142(58.4 \%)$ girls with some menstrual complaint had approached a physician at some time due 
to shyness, social limitations or lack of awareness regarding their significance. 30 girls had amenorrhea. On investigating, it was primary in 11 and secondary in 19 (Table 3). All cases of amenorrhea had reported to the Gynecology OPD.

Table 3: Etiology of amenorrhea.

\begin{tabular}{|ll|}
\hline Etiology of amenorrhea & No. of girls \\
\hline Primary amenorrhea & $\mathbf{1 1}$ \\
\hline Mullerian agenesis & 4 \\
\hline Imperforate hymen & 4 \\
\hline Transverse vaginal septum & 3 \\
\hline Secondary amenorrhea & $\mathbf{1 9}$ \\
\hline Polycystic ovarian disease & 8 \\
\hline Tubercular endometritis & 4 \\
\hline Hypothyroidism & 3 \\
\hline Stress induced & 4 \\
\hline
\end{tabular}

Table 4: Gynaecological complaints.

\begin{tabular}{|ll|}
\hline $\begin{array}{l}\text { Gynaecological complaints in } \\
\text { OPD patients }(\mathrm{n}=269)\end{array}$ & No. of patients \\
\hline Menstrual complaints & $111(41.2 \%)$ \\
\hline Amenorrhea & $30(11.1 \%)$ \\
\hline Vaginal discharge & $41(15.2 \%)$ \\
\hline Breast lump/discomfort & $28(10.4 \%)$ \\
\hline Pain abdomen/distension & $12(4.4 \%)$ \\
\hline Dyspareunia & $2(0.7 \%)$ \\
\hline Pregnancy/abortions & $34(12.6 \%)$ \\
\hline Post coital bleeding & $6(2.2 \%)$ \\
\hline Vulval hematoma & $4(1.4 \%)$ \\
\hline Sexual assault & $1(0.3 \%)$ \\
\hline
\end{tabular}

Other complaints included abnormal vaginal discharge in $41(15.2 \%)$ girls, lump in the breast in $28(10.4 \%)$ (Table $4)$.

There were 34 cases of teenage pregnancy. Out of which 16 had unsafe abortions, 7 had full term vaginal delivery, 5 had preterm vaginal delivery and 6 antenatal cases were managed conservatively. 19 of these 34 girls were anemic. 2 girls expired secondary to septic abortion.

\section{DISCUSSION}

Adolescent girls in our country are an especially vulnerable group with respect to reproductive and sexual health related problems. Although few studies have been done in India, considering the heterogeneity of the population involved, there is a need to conduct surveys appropriate to the specific needs of the this group.

Our study population consisted predominantly of urban based, unmarried school going girls with mean age of 16 years. $75 \%$ belonged to middle and upper socio-economic strata with access to television, radio, magazines and books. $25 \%$ were from poor socio economic class.
More than half $(58 \%)$ of the girls had knowledge about some method of contraception, most commonly oral pills, condoms and intrauterine devices. $70 \%$ were aware of sterilization procedures. . Grover et al reported that $62 \%$ girls were aware of condoms, $15 \%$ about oral contraceptive pills, $7.5 \%$ about safe period and $3 \%$ about intrauterine device. ${ }^{2}$ This reflects the paucity of awareness programs regarding family planning and contraception methods despite various ongoing programs initiated by the government. Since these young women will soon be initiated into marriage and child bearing, there is need to further empower them by increasing awareness so that they are able to make independent decisions regarding their fertility.

In the present study, $60 \%$ girls had awareness of HIV/AIDS as compared to only $14 \%$ girls knowing about other STD/RTI. However, in girls who were aware of HIV/AIDS, the knowledge was superficial. They had incomplete knowledge about the disease, its mode of transmission, methods of prevention and finally the social impact of the disease. In similar studies, it was revealed that $88 \%$ urban, educated girls had knowledge of AIDS and only $16 \%$ knew of STDs. ${ }^{3}$ A study by Gupta et al amongst rural adolescents found that only $18 \%$ were aware of STDs. ${ }^{4}$

These studies reveal that awareness regarding HIV and STDs is very low in adolescent girls both in rural and urban areas. This emphasizes the need to also stress on STD/RTI while conducting programs on HIV/AIDS.

Though the youth (15-24 years) form $19.2 \%$ of our population, they account for $31 \%$ of AIDS burden. Increasing awareness in this segment of the population regarding various STDs and HIV will also help in controlling the spread of HIV in India.

The most commonly cited source of information for reproductive health matters were friends followed by media, literature and family elders. Only in $1.4 \%$ girls, school teachers bridged the gap. Also, qualified medical professionals were not the direct source for dissemination of any information. The adolescents had to rely on peers and media which are not reliable sources. The lack of contact with health workers, paucity of adolescent friendly clinics and lack of such information in the school curriculum is thus highlighted.

This lack of awareness had resulted in problems such as teenage pregnancy (34 cases). Of these, 16 girls landed in unsafe abortion. 2 expired as a result of septicemic shock. Gardner (1995) estimated that one third to half of adolescent maternal deaths are due to infection, especially unsafe abortion. ${ }^{5}$ Even, in school going girls from urban background, such information is lacking. Thus, stressing the need to have adolescent friendly clinics at accessible places and introducing sexuality education in the school curriculum. 
The present study shows that menstrual disorders are the commonest pubertal problem faced by adolescent girls. Normal menstrual cycles were observed in $78.4 \%$ adolescents under study. Goswami et al, also observed that menstrual disorders are the commonest gynaecological problem of adolescent girls. ${ }^{6}$ Menstrual problems were reported in $21.5 \%$ young girls. They ranged from amenorrhea to menorrhagia, dysmenorrhoea being the commonest problem. Dysmenorrhea is the commonest menstrual problem faced by young girls. ${ }^{7,8}$

Since young girls usually rely on their mothers/sisters for such health problems, there is need to increase awareness about normal physiology not only among adolescents but also their parents so that such needs can be addressed at the appropriate time.

The findings of the present study indicate a lack of awareness and neglect among adolescent girls regarding sexual and reproductive health, even in urban areas. In rural areas, the situation is worse. A study by Gupta et al, showed similar results. ${ }^{4}$ This shows that though education level and literacy have increased, awareness regarding sexual health is still lacking.

\section{CONCLUSION}

Our study revealed substantial lacunae in the knowledge and attitude of young adolescent girls towards the reproductive and sexual health. Considering the fact that this study was conducted in a semi metropolitan city which also is the capital of the largest and most populous state of our country, the situation becomes more concerning. Though over the years, there has been an improvement in the awareness regarding sexual and reproductive health issues among adolescents yet there are no precisely aimed strategies to provide knowledge to this segment of the society. Apart from technical and medical issues, the major reason that comes up is the social stigma and taboo attached to the problem.

Identifying and accepting the problem is the first step in taking remedial steps. This study reinforces the requirement of adolescent friendly clinics, introduction of sexuality education in schools, increasing awareness through different forms of media, need for parents and siblings to provide a friendly environment where such matters can be discussed.
Funding: No funding sources

Conflict of interest: None declared

Ethical approval: The study was approved by the Institutional Ethics Committee

\section{REFERENCES}

1. Strategy Handbook. Rashtriya Kishor Swasthya Karyakram. Adolescent Health Division Ministry of Health and Family Welfare Government of India. 2014. Available at: https://www.dropbox.com/s /0oj4p422y7st4ku/RKSK\%20Strategy\%20Handbook .pdf.

2. Grover S, Garg N, Rupali. Awareness about reproductive health, contraceptive methods, STDs including HIV/AIDS, and HPV vaccine, among adolescent girls in district Faridkot in Punjab. Int $\mathbf{J}$ Reprod Contracept Obstet Gynecol. 2017;6(5):20039.

3. Watsa MC. A study of knowledge attitudes, beliefs and practices among urban educated Indian Youth. Youth Sexuality. F.P.A.I. (S.E.C.R.T.); 1994.

4. Gupta J, Martinez J, Smith R. High prevalence of genital tract human papilloma virus infection in female adolescent. J Pediatr. 1998;82(4):604-8.

5. Gardner R. Female adolescent health care: International perspective, In: Reproductive health care for women and babies: Analysis of Medical, Economic, ethical and Political issues, New York: Oxford University Press. 1995:40-56.

6. Goswami S, Dutta R, Sengupta S. A profile of adolescent girls with gynaecological problems. J Obstet Gynaecol India. 2005;55(4):353-5.

7. Joshi BN, Chauhan SL, Dondel UM, Tryambake VH, Gaikwad NS, Bhadoria V. Reproductive health problems and health seeking behaviour among adolescents in urban India. Indian $J$ Pediatr. 2006;73:509-13.

8. Singh MM, Devi R, Gupta SS. Awareness and health seeking behaviour of rural adolescent school girls on menstrual and reproductive health problems. Indian J Med Sci.1999;53(10):439-43.

Cite this article as: Sharma $S$, Sharma $P$.

Reproductive health problems and their awareness among adolescent girls: a clinical study. Int J Reprod Contracept Obstet Gynecol 2019;8:3870-3. 